\title{
El uso de referentes históricos en la prensa. Los atentados terroristas del 13 de noviembre de 2015 en París y la prensa española. Los casos del ABC, EI Mundo y EI País
}

\author{
Iñigo Fernández Fernández ${ }^{1 *}$
}

\begin{abstract}
Resumen
En este artículo se muestra cómo algunos de los escritores de los periódicos $A B C$, El Mundo y El País hicieron uso de los referentes históricos para compartir con los lectores, al calor de los hechos, sus posicionamientos y reflexiones en torno a los atentados terroristas que tuvieron lugar en París el 13 de noviembre del 2015. Para tal efecto, durante diez días se hizo un seguimiento de las secciones de "editorial" y "opinión" (blogs oficiales incluidos) en los periódicos citados, con el fin de encontrar los referentes históricos utilizados y, posteriormente, detectar y estudiar aquellos que resultaron ser los más habituales, a saber: la llustración, la Segunda Guerra Mundial y los ataques terroristas cometidos en Estados Unidos, España e Inglaterra entre los años 2001 y 2005. Abstract

This article shows how some of the writers of the newspapers $A B C$, El Mundo and El País used, at the heat of the moment, historical references to share with readers their positions and reflections on the terrorist attacks that took place in Paris on November 13th, 2015. For that effect, a daily follow-up was made during ten days for the sections of "editorial" and "opinion" (official blogs included) of the cited newspapers in order to find the historical referents used and to study those that were the most common, namely: The Enlightenment, World War II and the terrorist attacks committed in the United States, Spain and England between 2001 and 2005.
\end{abstract}

\section{Palabras Clave}

Historia, Periodismo, Referente histórico, Terrorismo, París

Keywords

History, Journalism, Historical reference, Terrorism, Paris

${ }_{1}^{1}$ Profesor-investigador de la escuela de comunicación de la Universidad Panamericana, campus Ciudad de México.

*Autor para correspondencia: infernan@up.edu.mx

\section{Introducción}

Muchos atribuyen a Philip L. Graham, director de The Washington Post entre 1946 y 1963, la definición del periodismo como "el primer borrador de la historia". Si bien hoy la frase resulta trillada y se ha convertido en un lugar común, lo cierto es que también pone de manifiesto la idea de que hay "algo" que une a la historia y al periodismo.

En el campo de la historia, esta relación ha transcurrido por dos derroteros bien diferenciados: el de la información y el del objeto del estudio. Cuando los historiadores se empezaron a interesar por la prensa, lo hicieron, en principio, porque vieron en ella una fuente generosa de información para estudiar el pasado (fechas, datos, opiniones, cifras, etc.). Con los años, esta manera de concebirla fue complementada por una perspectiva diferente que partía de la base de que los periódicos resguardados en las hemerotecas también eran productos culturales y materiales que reflejaban distintos tipos de prácticas a lo largo del tiempo (consumo, distribución, producción, recepción, tecnológicas, etc.) y que representaban 
perspectivas sobre procesos estructurales de corta y mediana duración. Fue así como, por méritos propios, la prensa devino en un objeto de estudio para la historia.

Pero esta relación también posee un carril de contraflujo, una vía en la que desde el surgimiento de los primeros diarios en el siglo XVIII (Weill, 1962) y hasta nuestros días, los periodistas han tomado como apoyo a la historia para redactar artículos, crónicas, editoriales, entrevistas, notas, etcétera; todos ellos ejercicios con los que informan al público a la par que fijan su postura en momentos y temas de interés para la sociedad. En estos casos, la historia deja de tener un carácter contextual para adquirir otro de tipo argumentativo; cesa de ser un auxiliar en las explicaciones para ser cimiento de un razonamiento más íntimo y profundo.

En esta relación entre la historia y el periodismo, aquí interesa, especialmente, el último punto; el de la apropiación de la primera en manos del segundo por todo lo que representa. En principio, se trata de una tarea en la que quien escribe toma postura frente a algo, se "desnuda" ante el lector cuando defiende sus convicciones o cuestiona las ajenas. Es, del mismo modo, el momento en el que el discurso propio debe ajustarse al institucional y apoyar al medio ciñéndose lo más posible a su línea editorial. Por último, estas dos situaciones condicionan el uso individual e institucional de ciertos referentes históricos para construir explicaciones. Desde este punto de vista, no importa el uso, o abuso, que en los periódicos se haga de la historia, lo que interesa es, al menos, presentar un breve esbozo de la manera como este fenómeno tiene lugar en ellos.

Como consecuencia de lo anterior, en este escrito se presenta un ejemplo del uso de la historia en la prensa escrita. Los puntos de partida son los atentados que acontecieron en París el 13 de noviembre del año 2015 así como la cobertura que hicieron de los mismos tres periódicos españoles: $A B C$, El Mundo y El País ${ }^{1}$. Para tal fin, se realizó un seguimiento

\footnotetext{
${ }^{1} \mathrm{El} A B C$ fue fundado el $1^{\circ}$ de enero de 1903 por el periodista Torcuato Luca de Tena y Álvarez Osorio. Virginia López de Maturana señala que "se caracteriza por ser un periódico conservador, monárquico y católico" y el público al que históricamente se ha dirigido corresponde al de clase alta y, en particular, al de sus intelectuales. El País fue fundado por Juan Luis Cebrián, Jesús de Polanco y José Ortega Spottorno al inicio de la transición española, y salió a la luz el 4 de mayo de 1976. Si bien en un principio su línea editorial era de tendencia social demócrata, Armañanzas y Díaz Noci señalan que con los años "[... ] se le ha ido enturbiando el país real; la larga lista de denuncias de corrupción lanzadas contra el Gobierno socialista le ha aguado la fiesta; el apoyo que ha dado a ese partido, ahora difícil de defender". Por su parte, $E l$ Mundo inició sus trabajos el 23 de octubre de 1989 por Alfonso de Salas,
}

de diez días (del 13 al 22 de noviembre) de las secciones de "editorial" y "opinión" (blogs oficiales incluidos) ${ }^{2}$ para responder a dos preguntas: ¿cuáles fueron los referentes históricos utilizados en cada publicación? Y ¿cuáles fueron los más recurrentes en cada una de ellas?

Se determinó realizar este ejercicio con la prensa española en virtud de que Madrid es una ciudad que sufrió atentados terroristas en marzo de 2004, lo que le permitió a la prensa española interesarse en lo sucedido en París y darle, al mismo tiempo, una significación e interpretación especiales. La elección de los periódicos respondió a que estos son los de mayor importancia en España, poseen presencia nacional y cuentan con líneas editoriales diferenciadas; el marco temporal de diez días comprende desde el instante en el que se dieron las primeras noticias de los atentados hasta el momento en el que estas perdieron protagonismo en los diarios. Por último, el uso de las secciones mencionadas parte del interés por identificar las primeras y, por ende, más espontáneas alusiones a los acontecimientos y a los usos del pasado por parte de los editorialistas de estos diarios para explicar un evento extraordinario a la luz de la historia.

Se sostiene, a manera de hipótesis, que el uso que los editorialistas dieron a la historia para explicar los hechos de París se dio bajo la perspectiva de la historia como maestra de vida, por "la cual el ser humano está implicado por su pasado, por un pasado que lo afecta, no moral, sino existencialmente" (Nava, 2005, 174) y que, al mismo tiempo le permite dotar de sentido al presente en el cual se halla sumido. Visto así, el uso de referentes pretéritos se transforma en una historia viva que se repite al tiempo que permite entender el mundo en el que vivimos, en general, y las disrupciones que eventualmente lo cimbran, en particular.

Balbino Fraga, Juan González, Melchor Miralles, Pedro J. Ramírez y Carlos Zayas. Para María José Canel, su línea editorial se define como la de un periódico que aspira a ser " $[\ldots$... progresista, comprometido con la defensa del actual sistema democrático, las libertades públicas y los derechos humanos recogidos en la declaración Universal promulgada por las Naciones Unidas y en la convención Europea de los Derechos Humanos". Cfr. López de Maturana, V (2005, junio 15). ABC ante la cuestión vasca en la Transición y la Democracia (1975-2001). Recuperado de http://argonauta.revues.org/1197 y consultado el 13 de junio de 2016; Armañazas, E. y Díaz Noci, J. (1993). Periodismo y argumentación. Géneros de opinión, Bilbao: Universidad del País Vasco, p. 183, y El Mundo (s. f.). Principios ideológicos. Recuperado de http://www.elmundo.es/sociedad/unidadeditorial/principiosideologicos.html, el 13 de junio de 2016.

${ }^{2}$ En contraposición, las notas informativas y los reportajes, si bien son ejercicios periodísticos que pueden brindar mayor información al lector, carecen de esa espontaneidad que las secciones de "editorial" y "opinión" presentan al calor de los hechos. 
Tanto las preguntas de investigación como la hipótesis planteada condujeron a realizar un ejercicio de selección de aquellas editoriales y notas de opinión en las que se recurriera a la historia para brindar explicaciones, lo que representó cerca de una tercera parte de los materiales revisados. En este sentido, debe aclararse que cuestiones como el uso pertinente o tendencioso de los referentes, la precisión de los datos contenidos en estos o los anacronismos en su aplicación y explicación no se excluyen del texto, por tratarse de elementos propios del fenómeno estudiado.

Por último, el autor aclara que su labor quedaría trunca si no estuviese precedida de una reflexión sobre el carácter limítrofe que posee la relación historia-periodismo; una disquisición que vaya de lo explícito hacia lo implícito, que parta de las especificidades propias de ambas disciplinas para destacar los ámbitos que les son comunes y que les permiten entablar un diálogo desde la óptica de los usos que hace la prensa de la historia.

\section{La relación entre la historia y el periodismo}

Las diferencias que sostienen ambos campos en forma y fondo, resaltan a todas luces. La primera, y más clara, responde al aspecto de la temporalidad. Aguilera y Durán (2014) apuntan que, en tanto que el periodista es un cronista del presente, el historiador hace lo propio con el pasado. Dentro de esta línea, pero yendo más lejos, se puede decir que la historia se interesa por estudiar y hacer comprensible la experiencia humana a lo largo del tiempo -con todo lo que ello representa-, en tanto que el periodismo difunde, interpreta, ordena, recopila y selecciona contenidos de actualidad.

Otra de las discrepancias tiene que ver con el discurso que articulan. En cuanto a la manera de estructurarlo, el periodismo se apoya en el artículo, la crónica, la entrevista, la noticia y el reportaje, en tanto que la historia recurre básicamente al ensayo. De igual manera, Abrahamson (2002) señala que mientras que el historiador inicia el proceso de investigación y escritura a través del uso de una premisa que explique la realidad pasada, al periodista le enseñan a rehuir al uso de cualquier tipo de premisa, lo que incide directamente en los tiempos de producción pues mientras que al primero le lleva meses escribir un artículo, el segundo puede producir un mayor número de textos en el mismo tiempo (Delano, 2011).

El tono en el que periodistas e historiadores escriben también es dispar. Abrahamson reflexiona sobre los modelos estándar de noticia-escritura y de "cómo los periodistas tratan de adaptar su escritura a esos modelos"; en cambio, considera que "la historia está más definida por el método y estructura que por el tono de la escritura misma" (2002, p. 4), es decir, los aspectos formales de la disciplina limitan más al historiador que al periodista al momento de escribir.

El proceso de producción también es distinto. El trabajo periodístico tiene una naturaleza colaborativa en la que la labor del reportero se debe sumar a la de otros compañeros (director, subdirectores, redactores, jefes de secciones... En el caso de un periódico impreso). En cambio, la tarea del historiador tiende a ser más aislada pues, a reserva del apoyo de los asistentes y de los colegas, gran parte del peso de la investigación, y de la responsabilidad que conlleva, recae en sus hombros.

A pesar de lo anterior, los vínculos entre la historia y el periodismo parecen haber fascinado a un mayor número de estudiosos en América y Europa, tal vez como consecuencia de que esta relación no resulte tan evidente y, en consecuencia, requiera de explicaciones.

Delano (2011) se remite al pasado para rescatar los orígenes de los lazos que mantienen ambas disciplinas. Apunta que uno de los primeros cursos de grado de periodismo en Estados Unidos inició sus actividades en 1878 y fue impartido, aunque con un cierto desdén, en el departamento de Historia de la Universidad de Missouri. Ello no debe extrañarnos si consideramos que el siglo XIX se caracterizó, entre otras cosas, por el surgimiento formal de la ciencia tal como hoy se concibe.

Por su parte, Conboy discrepa con Abrahamson al reconocer que los historiadores muestran una mayor preocupación por el lenguaje y los discursos que articulan sus investigaciones, lo que les ha motivado a acercarse a los textos periodísticos en tanto que la labor de los periodistas se encuentra presente en la historia:

en los marcadores de los ritmos de nuestra experiencia de lo cotidiano, en su rutinización de los aniversarios, obituarios, monumentos 
conmemorativos y cómo algunas de estas experiencias del pasado están mediadas por el periodismo como piedras angulares en las identidades tanto y editorial como nacional (2011, p. 507).

De igual modo, para Conboy esta relación tiene otros matices que se evidencian a través de la necesidad comercial de la prensa por tener un conocimiento para hacer su planificación futura, el uso de la voz popular como un recurso histórico que le permita ganar en credibilidad a la par que relacionarse con los lectores y difundir la concepción de que los medios de comunicación son equipos que registran hechos que con el tiempo se convertirán en una historia común.

Desde la perspectiva de Eiroa, las convergencias son varias e inician con el posicionamiento común que tanto la historia como la prensa presentan al iniciar sus labores. Para la investigadora, la búsqueda del dato y de la fuente lleva a que periodistas e historiadores coincidan en "[... el el afán por el rigor, la exactitud del dato y la contrastación de las fuentes, alejándose de la ficción o la ambigüedad en la elaboración de sus textos" (2014, p. 256); afirmación a la que también se suman Aguilera y Durán (2014). Eiroa también señala que las dos disciplinas dejan testimonios para las generaciones venideras, si bien evita adentrarse en la discusión sobre la intencionalidad con la que una y otra legan los hechos.

Ambas se caracterizan por ser lo que Nerone define como "disciplinas indisciplinadas". Los periodistas construyen su disciplina con las noticias en tanto que los historiadores lo hacen con el pasado común, y ambos han creado los mecanismos necesarios para que sus saberes se encuentren por encima de las creencias populares. Sin embargo, la parte de la indisciplina se origina cuando historiadores y periodistas se percatan de que, a pesar del esfuerzo anterior, los miembros de la sociedad se implican e intervienen en estos saberes pues "todo el mundo reconstruye continuamente una imagen del pasado común mientras consume representaciones vernáculas [o populares] del mismo en la cultura popular y en el discurso político" (2013, p. 17).

Un artículo básico para comprender los vínculos entre el periodismo y la historia desde la perspectiva del primero es $A$ Reservoir of Understanding. Why Journalism Needs History as a Thematic Field, del investigador alemán Horst Pöttker
(2011). En él, defiende la idea de que una de las funciones sociales de la historia es informar y que, en ese sentido, ayuda al periodismo tanto en el proceso de contextualización de su labor como para sobrevivir a los retos propios de la profesión $\mathrm{y}$ a aquellos generados por los medios digitales.

Pöttker parte de la premisa de que los medios de comunicación digitales han cambiado la función social del periodismo, de tal manera que este ha ido dejando poco a poco su labor informativa para adquirir otra más de carácter orientativo, de ahí que la historia le ayude a tomar eventos del pasado, explicarlos y así permita a los lectores entender de mejor manera el presente $y$, en particular, el carácter contingente que poseen las circunstancias culturales y políticas vigentes.

Para tal fin, Pöttker apunta que hay tres visiones de la historia (que retomó, a su vez, de Nietzsche) con las que el periodista puede trabajar (2011, pp. 525-530). La primera es la crítica, que permite al ser humano confrontar su mundo, cuya concepción es cambiante pues la sigue modelando a lo largo de su existencia, con el pasado referido por los historiadores. En este sentido, se entiende que el presente es lo opuesto al pasado. La segunda es la de anticuario, que se basa en la idea de que el presente es un producto, o variación, del pasado de tal manera de que en lo pretérito se pueden encontrar aún las "huellas de nacimiento" de lo actual. Esta propuesta implica que los cambios en el comportamiento, valores y normas son graduales y visibles sólo de manera intergeneracional. La última es la monumental, que plantea que el pasado y presente poseen una base común que se plasma en una ejemplaridad atemporal que rescata e idealiza los grandes sucesos del pasado al tiempo que los presenta como modelos a seguir en la actualidad.

Una vez vistos los puntos de encuentro y de desencuentro entre ambas disciplinas, es posible entrar de lleno al análisis del objeto de estudio de este artículo.

\section{Los atentados del 13 de noviembre de 2015 en París. La prensa española y el uso de la historia para explicarlos}

En la noche del viernes 13 de noviembre de 2015 la ciudad de París sufrió una serie de ataques terroristas coordinados. A las 21:16 horas hubo una explosión en las afueras del 
Estadio de Francia mientras se disputaba el partido entre las selecciones local y de Alemania. Entre las 21:30 y 21:52 horas tuvo lugar un tiroteo en la calle Bichat (21:20 horas); cuatro terroristas entraron en el teatro Bataclan, dispararon contra la multitud que se había reunido ahí para asistir el concierto de Eagles of Dead Metal y tomaron como rehenes a los supervivientes. Simultáneamente, un grupo armado atacó el restaurante Le Petit Cambodge y el bar Le Carrillon, en tanto que un atacante en solitario hizo lo propio en el bar Á la Bonne Bierre. A las 21:45 horas otro agresor disparó contra los comensales del restaurante Le Comptoir Voltaire y cinco minutos más tarde ocurrió algo similar en el bar $L a$ Belle Equipe. A las 00:20 horas del sábado 14 de noviembre la policía francesa tomó por asalto el teatro Bataclan, liberó a los rehenes y mató a cuatro de los terroristas. El número total de víctimas fue de 130 muertos y 368 heridos.

El Estado Islámico se atribuyó la responsabilidad de estos actos como respuesta a los ataques que la fuerza aérea francesa llevaba a cabo en Irak y Siria. Con el paso de los días, los servicios de inteligencia francesa hicieron un hallazgo perturbador pues de los diez terroristas, ocho eran europeos (seis franceses y dos belgas). De los dos restantes, que no pudieron ser identificados, se cree que eran de origen sirio y que entraron a Europa por Grecia en calidad de refugiados.

Si bien la noticia impactó al mundo, el efecto fue mayor en España pues hizo recordar los ataques del 11 de marzo de 2004 en los que una célula yihadista atentó contra el sistema de trenes de la red de cercanías de Madrid matando a 190 personas. Como consecuencia de ello, no resulta extraño que la cobertura que dieron los periódicos españoles a lo sucedido en París fuera amplia y generosa en noticias, cierto, pero también en análisis que surgieron a la luz de los hechos y a la sombra del recuerdo y en donde el uso de la historia fue fundamental para que los editorialistas contextualizaran y defendieran sus ideas.

La revisión propuesta comienza con el $A B C$. En sus páginas se encontraron comentarios que mayormente están relacionados con eventos sucedidos en los últimos sesenta años, si bien ello no excluye el uso de otros acaecidos anteriormente, como son los casos de la Segunda Guerra Mundial y la Ilustración.

En primer lugar, se hallaron referencias a otros tres atentados terroristas ocurridos al alba del siglo XXI: el del
11 de septiembre de 2001 en diversos puntos de Estados Unidos, el del 11 de marzo de 2004 en Madrid y el del 7 de junio de 2005 en Londres. Ramón Pérez Maura recurre a ellos para contextualizar el ataque en París pues comenta que "Estados Unidos sufrió el 11-S, [...], en Europa hemos visto atentados de todo tipo en Londres el 7-J de 2005, en Madrid el 11-M de 2004" (2015, noviembre 18), si bien atribuye los dos últimos, al igual que los perpetrados en Francia, al "buenismo occidental", es decir, a las posturas de aceptación y tolerancia que ciertos grupos políticos defienden y promueven ante el islam en el Viejo Continente.

Por su parte, Antonio Burgos ve en dichos referentes la manifestación de algo más profundo, el inicio de una nueva era pues "tampoco supimos que había empezado la Tercera [Guerra Mundial] aquella tarde de septiembre de 2001 en que nos llamaron para decirnos [...] que parecía que una avioneta se había estrellado contra las Torres Gemelas" (2015, noviembre 16). Desde su perspectiva, el 11-S marcó el inició de un estado de guerra permanente en el que, primero, los atentados de Atocha y del metro de Londres y, después, los de Francia, en el 2015, son testimonios fehacientes del mismo. Edurne Uriarte también comparte esta idea (2015, noviembre 14) y apunta que lo sucedido en Estados Unidos ha generado dicha situación de guerra continua, misma que representa, en cierto sentido, el fracaso de Europa en su afán por negarse a reconocer dicha realidad bélica al tiempo que por querer dar solución a este problema únicamente desde el ámbito intelectual y a través del principio de integración de los grupos musulmanes (a los que la autora denomina como "fanáticos") en el seno de las sociedades europeas.

José María Carrascal realiza un recorrido histórico para explicar otra arista de la situación al tiempo que para dar aliento en lo que, para él, es implícitamente una guerra. A la pregunta de ¿por qué Francia fue atacada si dio asilo al Ayatolá Jomeini? ${ }^{3}$, responde que porque es la cuna del pensamiento ilustrado y de sus máximas de libertad, igualdad y fraternidad. De cierto modo esta reflexión convierte a Francia en víctima de su propio pasado y de su ser histórico pues, parecería ser, que hoy está muriendo precisamente por aquellos principios que tanto ha defendido a partir de $1789 \mathrm{y}$ que representaron la irrupción de la modernidad en occidente.

\footnotetext{
${ }^{3}$ En occidente se considera a Ruhollah Musaví Jomeini el detonante del integrismo islámico y del que el yihadismo es su manifestación más visible en la actualidad.
} 
Sin embargo, no todo está perdido para Carrascal pues la historia "reciente", encarnada en la derrota del "nazismo hitleriano y el comunismo estalinista", demuestra que la democracia, en un sentido atemporal y teleológico, ha sido, y debe seguir siendo, capaz de acabar con cualquier dictadura (2015, noviembre 19).

El pasado bélico europeo también se encuentra presente en las páginas del diario. A la mención de Hitler recién referida se suma la presentada por Ramón Pérez Maura, quien se remite al año de 1939 para preguntar a los lectores si entonces $¿$ el problema se encontraba en el nacionalsocialismo o en Alemania? Y si ¿acaso todos los alemanes eran nazis? Sus respuestas, que señalan que el problema estaba en la ideología -no en el país- y que no todos los alemanes eran nazis, son un recurso retórico para postular una de las ideas centrales de su reflexión: "hay que enfrentar lo que el islamismo está haciendo en nombre del islam como en 1939 hubo que enfrentar lo que los nazis hicieron en nombre de Alemania" (2015, noviembre 18). Se trata, pues, de un paralelismo interesante que relaciona dos conceptos - "islam" y "nazismo"- a través del terror sin que los vínculos entre ambos no sean tan evidentes.

Antonio Burgos aborda el tema a través del reconocimiento de uno de los problemas propios de nuestra experiencia histórica: la imposibilidad que tenemos los seres humanos de determinar a priori si los sucesos que vivimos serán trascendentes en el futuro. Comenta que "seguro que cuando mataron al Archiduque en Sarajevo [las personas] no sabían que había empezado la Gran Guerra. Ni que cuando Hitler invadió Polonia había comenzado la II Guerra Mundial" (2015, noviembre 16). Con ello advierte a los lectores que abran los ojos y que tomen perspectiva pues están presenciando lo que será considerado por los historiadores del futuro como un hecho trascendental: la Tercera Guerra Mundial.

En lo que respecta a $E l M u n d o$, coincide con el $A B C$ en el uso de algunos referentes históricos pero, a diferencia de este, cuenta con una mayor variedad de los mismos. Por cuestiones de espacio sólo se describen aquí los dos que poseen un mayor peso específico en el periódico.

El referente más importante es, sin lugar a dudas, el 11-M. Algunos editorialistas se apoyan en él para tender un puente entre lo sucedido en Francia y lo acontecido en España al tiempo que para reflexionar sobre el presente español. Para
Federico Jiménez Losantos, una consecuencia de los atentados de Madrid fue que "media España aceptó encantada que los terroristas tenían razón, siempre que acertaran con su objetivo, que no podía ser otro que evitar que mandara la otra media" (2015, noviembre 18), lo que es una alusión a las repercusiones que tuvo el atentado en las elecciones generales del 14 de marzo de 2004 y, al mismo tiempo, es una mención a la marcada división política española que se vivía en noviembre de 2015 y que quedó de manifiesto en las elecciones generales del 20 de diciembre de ese año y, en particular, con el reparto de escaños que derivó de ellas y que obligó a la celebración de un nuevo proceso electoral el 26 de junio de 2016.

Por su parte, Vicente Lozano hace eco de lo sucedido en 11-M para exaltar la reacción de los franceses que salieron del estadio de Francia cantando el himno e inundaron las redes sociales con su bandera, en contraposición con los españoles, quienes en el año 2004, al igual que en el 2015, consideraban a su himno y bandera como símbolos muy cercanos a la dictadura franquista (2015, noviembre 19). La esencia de este comentario se encuentra también en los textos de Arcadi Espada y David Jiménez, quienes sostienen que la diferencia entre los franceses y los españoles es que mientras que los primeros mostraron unidad tras los ataques terroristas, parecería que los segundos dejaron pasar esa oportunidad en su momento pues fueron "incapaces de dejar de lado las dos Españas" (2015, noviembre 15), un recordatorio claro de que las heridas causadas por la Guerra Civil seguían abiertas a más de 75 años de su final.

Otro referente utilizado por El Mundo es el de la Ilustración, cuyo nombre, autores e ideas son contrapuestos al Estado Islámico en una dicotomía de libertad contra represión, democracia contra totalitarismo, razón contra fanatismo o, más peligroso aún, occidente contra oriente. Así, la Ilustración es considerada como un continuo que conecta al pasado con el presente y que ayuda a darle sentido al segundo. En su editorial del 15 de noviembre, el periódico menciona que:

AL DÍA SIGUIENTE del atentado contra Charlie Hebdo, los franceses que se concentraron en la parisina plaza de la República para mostrar su rechazo al despiadado atentado en el que murieron 11 personas enarbolaban como única arma un libro cuyo significado resumía mejor que 
ninguno la identidad europea. Aquella mañana, el Tratado sobre la tolerancia en el que Voltaire reivindicaba el derecho al pensamiento libre contra la intransigencia religiosa se agotó en todas las librerías. La macabra respuesta a aquella provocación, se produjo el viernes [13 de noviembre] por la noche (2015, noviembre 15).

La estructura del párrafo inicial es interesante pues parte del pasado reciente -el ataque a Charlie $\mathrm{Hebdo}^{4}$-, se remite luego a un referente histórico lejano de corte fundacional -el Tratado sobre la tolerancia de Voltaire- y concluye regresando al presente para enfatizar la oposición existente entre la tolerancia y la intransigencia religiosas.

La figura de Voltaire, sin embargo, también tiene un uso distinto, pues Raúl del Pozo asume que los atentados de París fueron el inicio de una guerra entre Mahoma y este, "entre el ideal republicano que supera las etnias y las creencias y los inadaptados descendientes de emigrantes árabes". Su Voltaire no es el defensor de la tolerancia religiosa, más bien es el que con una notoria y supuesta preclaridad parecía advertir a Europa sobre un peligro futuro dado que en el siglo XVIII “el Corán gobernaba el África septentrional, desde el monte de Atlas hasta el desierto de Barca, todo Egipto, las costas del Océano etiópico, la Siria, el Asia Menor, el mar Negro y el mar Caspio, todo el imperio del Indostán, toda Persia y Egipto" (2015, noviembre 15).

A reserva de lo anterior, cierto es que la tolerancia religiosa es una manifestación de esa libertad que tanto identifica al espíritu ilustrado desde sus orígenes y hasta nuestros días y es por ello que también nos enfrenta a una problemática que es igualmente vigente: ¿esta libertad tiene límites? Pedro G. Cuartango recurre a la historia para responder a esta pregunta apuntando que "Edmund Burke dice unas palabras esclarecedoras [...]: hay un límite en el que la tolerancia deja de ser virtud". Cuartango rescata la crítica que el padre del liberalismo-conservadurismo británico lanzó contra los ilustrados en sus intentos por hacer a un lado los valores tradicionales franceses (honor, religión, etc.) para

\footnotetext{
${ }^{4}$ Charlie Hebdo es un semanario humorístico francés que sufrió un atentado el 7 de enero de 2015, cuando dos encapuchados — miembros del grupo Al Qaeda- entraron en sus oficinas y dispararon contra quienes se encontraban en ellas. El saldo fue de 12 muertos y 11 heridos.
}

defender la idea de que Europa concretó los sueños de los promotores de la Ilustración "tras varias décadas de exaltación de la pluralidad, la tolerancia y el progreso social" (2015, noviembre 16), si bien con ello fracasó, tal como lo evidencian los ataques ocurridos en París.

Una postura contraria se encuentra en la reflexión de Manuel Núñez Encabo. Al igual que varios de sus colegas se remonta a la Ilustración, aunque él centra su atención en la Declaración de los derechos del hombre y del ciudadano -aprobada por la Asamblea Nacional Constituyente francesa en agosto de1789- no sólo por considerarlo "tal vez el documento histórico más importante del reconocimiento de la dignidad de toda persona por el hecho de serlo", también por defenderlo como el medio "que ha permitido [...] ir acogiendo en Europa a inmigrantes de otros países del mundo desde el respeto mutuo" (2015, noviembre 19). De este modo, mientras que para otros el referente histórico de la Ilustración, particularmente en su principio de tolerancia, es un recurso que ayuda a entender la razón de los ataques terroristas de París, para Núñez Encabo representa la solución para erradicar la violencia. Hasta este punto, el trabajo se encuentra ante un referente y dos reflexiones encontradas que de él emanan.

En El País, por otra parte, resulta evidente una preferencia por el uso de otros tipos de referentes en comparación con los otros diarios. Los suyos suelen remitirse al siglo XX y tienen como origen la Segunda Guerra Mundial.

Esta conflagración es uno de los referentes más utilizados por la publicación. Así, Bernard-Henri Levy cita al diplomático y poeta francés Paul Claudel, quien en su diario el día 21 de mayo de 1935 apuntaba: “¿Discurso de Hitler? Se crea en el centro de Europa una especie de islamismo...", (2015, noviembre 17). Se trata de una cita cuyo uso resulta conveniente en el contexto posterior a los atentados y en el que se hace inferir al lector que el nacionalsocialismo alemán y el islamismo radical comparten su rechazo hacia la democracia y poseen una naturaleza violenta. Otra muestra más de que la relación entre ambos movimientos es tan sugerente como aparentemente obvia, o autorreferencial, es el hecho de que Culla publica en este diario un artículo llamado "Los nazis de Alá” (2015, noviembre 17) y en el que la única vez que utiliza la palabra "nazis" es justo en título de su editorial. De igual manera, la Segunda Guerra Mundial ayuda a apuntalar la idea de que el fenómeno de militantes suicidas tampoco 
es algo nuevo: Moisés Naím señala que en este conflicto "3.860 pilotos militares japoneses, los famosos kamikazes, se suicidaron intentado estrellar su avión contra un barco enemigo [...]" (2015, noviembre 14).

Otro referente histórico, de cuño más reciente, que aparece en las páginas de El País, es el de la guerra de Irak del año 2003. Recuérdese que aquel fue un conflicto polémico desde sus orígenes en virtud de que el gobierno estadounidense, encabezado por George W. Bush, sostenía que el gobierno iraquí de Saddam Hussein contaba con armamento químico. Pese al rechazo de la Organización de Naciones Unidas a declarar la guerra, Estados Unidos organizó una colación internacional, junto con Dinamarca, España, Italia, Polonia y Reino Unido, entre otros; con la que invadió la nación asiática el 20 de marzo del año 2003.

Dentro de este marco, y como previo a dicha intervención, se celebró en las islas Azores una cumbre en la que participaron George W. Bush (presidente de Estados Unidos), Tony Blair (primer ministro del Reino Unido), José María Aznar (presidente del gobierno español) y José Manuel Durão Barroso (primer ministro de Portugal). En esta "cumbre de las Azores", como fue nombrada la reunión por la prensa española, los participantes acordaron dar un ultimátum de 24 horas al gobierno iraquí para que destruyera su armamento químico como condición para evitar la guerra. Debe señalarse que esta cumbre generó críticas y divisiones al interior de España, al igual que ocurrió con la guerra en el seno de la sociedad estadounidense.

Para Baltasar Garzón y Dolores Delgado este hecho de la historia reciente del mundo fue el punto de partida de un integrismo islámico cuya última manifestación se encarnó en los atentados de París. Como consecuencia de lo anterior comentan que:

Han tenido que pasar 12 años para que Tony Blair haya reconocido que la guerra de Irak está en la base de la generación del terrorismo del Estado Islámico que, sin aquella acción ilegal y sin justificación, nunca hubiera aparecido. Ahora nos toca sufrir las consecuencias de cuño más reciente (2015, noviembre 16$)$.

Si bien la idea de que en este siglo XXI occidente, particularmente Europa, está cosechando lo que sembró en oriente tanto en los albores del presente como en los siglos anteriores a través de su expansión colonialista, lo cierto es que no todos comparten este parecer. Culla hace un uso coyuntural de este referente al vincularlo con el líder del partido Podemos, Pablo Iglesias, quien en ese momento expresó que "nada de pacto antiyihadista, admonición a no caer en la 'venganza' y una referencia a la invasión de Iraq, como si el espectro del 'trío de las Azores' justificase cualquier cosa, desde Madrid 2004 a París 2015”. En consecuencia, y tal como lo sentencia la autora, llegó el momento de dejar de culpar a occidente de gran parte de los males del mundo, de hacer a un lado la corrección política y plantar cara al terror islamista para erradicarlo de Europa (2015, noviembre 17).

Sin embargo, no todos los autores están de acuerdo con el uso de la guerra de Irak para datar el surgimiento del integrismo islámico. Luz Gómez se remonta a los años setenta del siglo pasado, cuando el régimen de Anwar el-Sadat fomentó las agrupaciones islámicas egipcias para frenar los cuestionamientos realizados por la izquierda en su país. Esta experiencia se vio favorecida con la invasión soviética a Afganistán (1979-1988), que generó en un escenario ideal para que los jóvenes islamistas del cercano oriente combatieran, con financiamiento norteamericano, a la potencia invasora (2015, noviembre 18). En cierto sentido, su postura se suma a la de que no hay que culpar del todo a occidente en la materia.

Este referente, sin embargo, sirve de puente para otro, el de los ataques terroristas previos en Estados Unidos y Madrid (curiosamente los de Londres no son mencionados). Los primeros, correspondientes al 11-S, marcaron un cambio fundamental en el mundo pues, para Luz Gómez, después de esta fecha "los atentados de la primera década del siglo XX revelan una 'democratización' de los objetivos de la yihad" (2015, noviembre 18), donde cualquier persona, más allá de su credo, origen o posición social, es una víctima potencial de los mismos. Para Moisés Naím el 11-S coincide de manera implícita con lo anterior y lo complemente considera que, a más de una década de este suceso, "las ideas sobre la naturaleza de la amenaza, sus causas y las mejores maneras de combatirla son confusas y motivo de álgidos debates" (2015, noviembre 14). 
A reserva de las dudas y de las discusiones, en El País el 11-S se volvió un referente para comprender el origen del Estado Islámico porque fue el primer ataque; fue el inicio de una historia que ha alcanzado su momento de mayor violencia con el 13-N francés. En el centro encontramos el 11-M, el que hasta entonces había sido el ataque más mortífero del Estado Islámico en Europa. Sobre este último, Vicente Olaya cuestiona su uso como referente histórico en virtud del presente y pone como ejemplo al monumento homenaje a las víctimas del 11-M -o "el cilindro desinflado", como él lo denomina-, que se encuentra en un estado total de abandono ante la impasividad de la sociedad y de los políticos españoles pues "a nadie le llama la atención [... el el monumento que debía guardar la memoria de los casi dos centenares de ciudadanos asesinados por el terrorismo yihadista en marzo de 2004" (2015, noviembre 17). Así, resulta válido cuestionarnos sobre el sentido que tiene que un país lamente lo sucedido en Francia sí parece haberse olvidado de un episodio igualmente trágico de su pasado reciente.

\section{A manera de conclusión}

La revisión anterior pone de manifiesto una serie de puntos en común, y otros de diferenciación, entre las reflexiones que los periódicos $A B C$, El Mundo y El País compartieron con sus lectores los primeros días que siguieron a los atentados terroristas de París.

El $A B C$ centra su interés en referentes de la historia reciente, particularmente en los atentados terroristas cometidos en Estados Unidos, España e Inglaterra (siglo XXI) y que a su vez sirven de sustento para que varios de sus autores se refieran al futuro, representado por una Tercera Guerra Mundial, siendo el único diario que utiliza el pasado para explicar un hecho del presente y hacer una proyección hacia el futuro. Del mismo modo, deja espacio para otros más distantes en el tiempo: la Segunda Guerra Mundial (siglo XX) y la Ilustración francesa (siglo XVIII). Un fenómeno similar se aprecia en $\mathrm{El} \mathrm{Mundo}$, diario que también centró su interés en el pasado cercano, en especial en los atentados acontecidos en Madrid en el 2004 y, en menor grado, en las ideas ilustradas. Por el contrario, El País posa su mirada en los referentes históricos del siglo XX, empezando por la Segunda Guerra Mundial, a la que le dedica más espacios que los diarios anteriores, y pasando por los atentados terroristas de Estados Unidos y Madrid y la invasión a Irak del año 2003.

La Ilustración y la Segunda Guerra Mundial son acontecimientos históricos que permiten a los periodistas establecer una dualidad que aparenta ser atemporal, o perenne, y que parece reflejarse en los atentados de París: la paz y la guerra, las luces y la oscuridad, la razón y la cerrazón. Mientras que se vincula al pensamiento ilustrado con occidente y los aspectos positivos de esta dicotomía, la Segunda Guerra Mundial, por su violencia, es asociada con oriente y el fundamentalismo islámico.

Se trata, pues, de referentes que se encuentran presentes en la memoria de la gente, ya sea por su proximidad temporal (como en el caso de los ataques de 2001, 2003, 2004 y 2005), o bien por su trascendencia histórica (Ilustración y Segunda Guerra Mundial), y que, además, gozan de un cierto consenso social ${ }^{5}$. Estas dos características facilitan la labor de los periodistas pues les permiten apoyarse en determinados hechos históricos sin tener necesidad de explicarlos a detalle a los lectores en general.

En las tres publicaciones se observa que el uso de estos referentes implica, por un lado, un interés por entender el presente de España, que se manifiesta en las comparaciones, críticas y menciones a hechos, personas y sucesos del aquí y del ahora. Pero, del mismo modo, representa un ejercicio de contextualización por parte de los editorialistas que implica tanto la defensa de convicciones - personales e institucionalespor parte de quienes escriben como la búsqueda en los tres diarios de la respuesta a la pregunta ¿y ahora cómo podemos dar solución al problema?

El uso de los referentes y perspectivas históricos lleva a los autores a plantear líneas de acción futuras en la más clara manifestación de la historia como maestra de vida. Más allá de los aspectos editoriales y postulados ideológicos con los que se encuentra alineada cada publicación, en las tres se identifican dos posibles caminos a seguir que se encuentran íntimamente ligados con lo expuesto en los párrafos anteriores: continuar con los trabajos de integración

\footnotetext{
${ }^{5}$ Se utiliza el término de "cierto" pues no todos los miembros de una sociedad comparten dicho consenso. Por ejemplo, los grupos de extrema derecha que se declaran herederos del movimiento nacional-socialista poseen necesariamente una visión de la Segunda Guerra Mundial distinta en comparación con la que tiene la mayor parte de las personas que dan vida a su sociedad.
} 
de los grupos islámicos en las sociedades europeas en lo que se desarrollan, más aún cuando sus miembros han nacido y viven en Europa; la otra, por contra, defiende el principio de que Europa deje a un lado lo "políticamente correcto" para combatir al integrismo islámico en cualquier terreno -incluida la propia Europa- a través del uso de la inteligencia e, incluso, de las armas.

Lo cierto es que, en este caso, la historia está llena de ejemplos y de referentes que lo mismo pueden servir para defender que para denostar ambas posturas. A final de cuentas, todo depende de la intención, intereses e ideas de quien se encuentra delante del teclado...

\section{Referencias}

Anónimo (15 de noviembre de 2015). Occidente debe luchar unido contra el terror del IS. El Mundo. Recuperado de http://www.elmundo.es/opinion/2015/11/15/5647a2 a4ca47410b728b4680.html

Abrahamson, D. (2002). Journalism v. History?, Clio, The Newsletter of the AEJMC History Division, 35/1, pp. 1,4, 7.

Aguilera Povedano, M., Durán Mañes A. (2014). El periodismo histórico: teoría y técnica de uso en la prensa española. Prisma social. Revista de ciencias sociales, 12, 1-40. Recuperado de http://www.isdfunda cion.org/publicaciones/revista/numeros/12/secciones/ tematica/pdf/t-01-periodismo-historico-0-44.pdf.

Armañazas, E. y Díaz Noci, J. (1993). Periodismo y argumentación. Géneros de opinión, Bilbao: Universidad del País Vasco.

Burgos, A. (16 de noviembre de 2015). Mírala cara a cara, que es la tercera. $A B C$. Recuperado de http://www.abc.es/opinion/abci-mirala-cara-cara-terce ra-201511160403_noticia.html

Carrascal, J.M. (19 de noviembre de 2015). Islamismo contra Ilustración. $A B C$. Recuperado de http://www.abc.es/opinion/abci-islamismo-contra -ilustracion-201511190241_noticia.html

Conboy, M. (2011). "Introduction”. Journalism Practice. 5/5, 506-519.

Cuartango, P. (16 de noviembre de 2015). La identidad desdichada. El Mundo. Recuperado de http://www.elmundo.es/opinion/2015/11/15/5648f216 46163ff8348b45a2.html

Culla I Clara, J. (17 de noviembre de 2015). Los nazis de Alá. El País. Recuperado de http://ccaa.elpais.com/ccaa/201 5/11/19/catalunya/1447960948_367273.html
Del Pozo, R. (15 de noviembre de 2015). Mahoma contra Voltaire. El Mundo. Recuperado de http://www.elmundo.es/opinion/2015/11/16/5648 cb6f46163ff6348b458f.html

Delano, A. (2011). Foreword. Journalism Practice. 5/5, 504-505.

Eiroa, M. (2014). Historia y periodismo: interrelaciones entre disciplina. Historia y comunicación social, 19, 253-264.

El Mundo (s. f.). Principios ideológicos. Recuperado de http://www.elmundo.es/sociedad/unidadeditorial/pr incipiosideologicos.html

Espada, A. (18 de noviembre de 2015). Marsellesas. El Mundo. Recuperado de http://www.elmundo.es/opinion/2015/11 /18/564ce04722601de36c8b45ae.html

Garzón, B., y Delgado D. (16 de noviembre de 2015). Viernes 13, terror en París. El País. Recuperado de http://elpais.com/elpais/2015/11/16/opinion/1447675 806_320307.html

Gómez García, L. (18 de noviembre de 2015). Más allá de París. El País. Recuperado de http://internacional.elpais.com/internacional/201 5/11/18/actualidad/1447857226_516033.html

Jiménez Losantos, F. (18 de noviembre de 2015). El terror arrojadizo. El Mundo. Recuperado de http://www.elmundo.es/opinion/2015/11/18/564b 88d5268e3efd738b4583.html

Jiménez, D. (15 de noviembre de 2015). Lo que el terror nunca podrá lograr. El Mundo. Recuperado de http://www.elmundo.es/opinion/2015/11/15/56479f c0ca47410a728b4677.html

Levy, B.H. (17 de noviembre de 2015). La guerra, manual de instrucciones. El País. Recuperado de http://internacional.elpais.com/internacional/2015/11/1 6/actualidad/1447704301_776551.html

Lozano, V. (19 de noviembre de 2015). Envidia de los franceses. El Mundo. Recuperado de http://www.elmundo.es/opinion/2015/11/19/564c bd1b22601dd26c8b4573.html

López Maturana, V. (2005). ABC ante la cuestión vasca en la Transición y la Democracia (1975-2001), en Argonauta, España, Junio de 2005. Recuperado de http://argonauta. revues.org/1197

Naím, M. (14 de noviembre de 2015). París: la guerra ya no es lo que era. El País. Recuperado de http://internacional.elpais.com/internacional/201 5/11/14/actualidad/1447532165_205160.html

Nava Murcia, R. (2005). Deconstruyendo la historiografía: Edmundo O'Gorman y La invención de América, en Historia y Grafía, 25, pp. 153-184.

Nerone, J. (2013). History, Journalism, and the Problem of Thruth, en Brennen, Bonnie (Ed.), Assessing Evidence in a Postmodern World, (pp. 17-31). Milwaukee: Marquette University. 
Núñez Encabo, M. (19 de noviembre de 2015). Religiones unidas frente al terrorismo. El Mundo. Recuperado de http://www.elmundo.es/opinion/2015/11/19/564cb8 1d22601d39448b466f.html

Olaya, V. (17 de noviembre de 2015). La triste metáfora del cilindro desinflado. El País. Recuperado de http://elpais.com/elpais/2015/11/17/opinion/1447788 519_852440.html

Pérez Maura, R. (18 de noviembre de 2015) El problema está en el Islam. $A B C$. Recuperado de http://www.abc.es/opinion/abci-problema-esta-isla m-201511180338_noticia.html

Pöttker, H. (2011). A Reservoir of Understanding. Why Journalism Needs History as a Thematic Field. Journalism Practice, 5/5, 520-537.

Regnault, F. (2015). 'Las cosas del amor'. Hipótesis sobre los recientes acontecimientos de París. Visto desde El Al. Lacán cotidiano, París 548, s. p. Recuperado de http://www.eol.org.ar/la_escuela/Destacados/LacanQuotidien/LC-cero-548.pdf.

Uriarte, E. (16 de noviembre de 2015). La guerra que ya no se puede eludir. $A B C$. Recuperado de http://abcblogs.abc.es/edurne-uriarte/public/post/laguerra-que-ya-no-se-puede-eludir-16673.asp/

Weill, G. (1962). El periódico. Orígenes, evolución y función de la prensa periódica, México: Unión Tipográfica Editorial Hispano Americana. 